\title{
MUERTE Y COMUNIDAD EN AMAICHA DEL VALLE (VALLES CALCHAQUÍES. TUCUMÁN)
}

\section{Marcela LÓPEZ MACHADO ${ }^{1}$}

\section{Resumen}

El presente artículo retoma -como consecuencia de un proceso de trabajo de campo realizado en Amaicha del Valle (Valles Calchaquíes. Tucumán)- las relaciones entre ritual, muerte y comunidad, con referencia a una movilización colectiva, llevada a cabo, principalmente por mujeres, luego del asesinato de una anciana comunera. Expone una categoría analítica central de la investigación, la de "territorialidad simbólica de género" que recoge los aspectos mas significativos de las relaciones entre esos tres conceptos para la construcción de una identidad comunitaria de los amaicheños.

Palabras clave: Muerte- Ritual- Territorialidad Simbólica. Identidad comunitaria

\section{Abstract:}

This article takes -as a result of a process of fieldwork in Amaicha del Valle (Tucumán Calchaquí.)- relations between ritual, death and community linked to collective mobilization, carried out by women, after the murder of an old commoner. It exposes a

1 CIC-UNR- Facultad de Humanidades y Artes. UNR (Argentina). mlomacha@,fhumyar.unr.edu.ar

Fecha de recepción del artículo: Febrero 2019

Fecha de evaluación: Mayo 2019 
central analytical category of research, that of "symbolic gender territoriality" which comprises the most significant aspects of the relations between these three concepts for building a community identity Amaicheña..

Keywords: Death -ritual -Symbolic Territoriality - community identity

\section{Resumé:}

Le présent article reprend - à la suite d'un processus de travail de terrain effectué à Amaicha del Valle (Valles Calchaquíes. Tucumán) - les relations entre rituel, mort et communauté, avec référence à une mobilisation collective, réalisée principalement par les femmes, après le meurtre-fémicide d'une personne âgée. Pièces a catégorie analytique centrale de la recherche, celle de «territorialité symbolique du genre » qui rassemble les aspects les plus significatifs de la relations entre ces trois concepts pour la construction d'une identité communauté des amaicheños.

Mots-clés: Territorialité Mort- Rituel- Symbolique. Identité Communauté

\section{1- Introducción}

La reflexión mas general que vertebra este artículo se refiere a que dentro del amplio campo que constituye la temática antropológica de la muerte es necesario realizar un conjunto de delimitaciones teórico-metodológicas para delinear ordenes de problema con especificidad disciplinar, mediante la investigación de situaciones concretas particulares que posibiliten estudios sobre la muerte $\mathrm{y}$, en este caso, algunas de sus repercusiones, en clave antropológica. En la medida en que la problemática de la muerte y todos los rituales y ceremonias que le van asociados, constituirían modalidades socioculturalmente diferenciadas de controlar lo azaroso, lo circunstancial o irreversible, que es percibido de modo dramático por el grupo, no considero que, el trabajo de quienes como antropólogos nos concentramos - de modo exclusivo o no- en lo relativo a la muerte deba orientarse hacia una autonomía temática.

En líneas generales, lo que pareciera ponerse en evidencia en el registro de las diversas formas socio-culturales asociadas con el tratamiento de la muerte sería un intento de 
restitución ritual de un cierto orden de hechos, que puede ser percibido como deshecho, a partir de la desaparición física de otro. Dicha desaparición parece poner en riesgo lo que sería una de las propiedades subjetivas con que percibimos la vida, su "naturalidad". Esta "naturalización", por el hecho de situar lo referido a la muerte en un contexto con repercusiones emocionales y simbólicas grupales muy intensas, parecería brindar en un nivel eminentemente práctico una pista importante para comprender algunos de los mecanismos identitarios que actúan en la constitución y consolidación de ese tipo particular de grupo social que suele denominarse como "comunidad".

En este artículo pretendo dar cuenta de algunas de las cuestiones puestas en juego a partir de un acontecimiento particular, un "evento crítico", extraordinario, que si bien, a diferencia de los rituales, son “...más vulnerables al azar y a lo imponderable...” y no por eso están “...desprovistos de estructura y propósito...” (Peirano, M; 2002: 8): me refiero a la muerte por asesinato de una anciana comunera de gran prestigio, miembro de la Comunidad Indígena de Amaicha del Valle. El registro de los episodios ligados a ese acontecimiento se produjo en el contexto de una investigación acerca de las implicaciones del género en la producción de las formas societales e ideológicas que caracterizan a la comunidad en la Comuna Rural de Amaicha del Valle.

La misma está basada en un trabajo etnográfico con permanencias eventualmente prolongadas en dicha villa y apela a una metodología participativa activa en el campo de investigación. Sin embargo, no se sustenta exclusivamente en premisas etnometodológicas; aunque no excluye, en absoluto, muchas de ellas.

Se orienta en la dirección señalada por Renato Rosaldo cuando afirma que

“...si el vicio de la etnografía clásica era el desprendimiento del desinterés ideal a la indiferencia verdadera; el vicio de la reflexividad actual es la tendencia para que el Yo abstraído, pierda la objetividad del otro culturalmente diferente (con lo cual ilustra) la precaución metodológica de la disciplina contra la atribución temeraria de las experiencias y categorías de uno mismo con los miembros de otra cultura” (Rosaldo, R. ,1991: 17-20). 


\section{2- $\quad$ Antropología y Muerte: Avanzando hacia una primera delimitación}

En líneas generales, el carácter de experiencia cotidiana y, a la vez, relativamente aleatoria y universal que caracterizan nuestra percepción de la muerte (Thomas, 1991:21) la ha hecho objeto de reflexión de disciplinas tales como la filosofía, la historia, la psicología, la sociología y la tanatología, entre otras; lo cual parece imponer una primera dificultad vinculada con la superposición de enfoques disciplinares que predominan en el encuadre conceptual al que los antropólogos podemos recurrir para abordar esta problemática, ya que si bien la Antropología la ha tomado desde una perspectiva etnográfica intercultural -desde sus primeros tramos- algunas de sus orientaciones conceptuales suelen provenir incluso, actualmente, de otros contextos teóricos.

No obstante, como ha indicado R. Rosaldo

"La muerte (...) posee la virtud de estar bien representada en la literatura antropológica..." donde ha probado “...ser un tema (...) muy fértil en la producción de relatos reguladores remotos.” (1991:60); los que, siguiendo "las normas clásicas "describen eventos específicos “...como si fueran rutinas culturales programadas y coloca al observador a una distancia mayor del observado" (1991:59)

determinando, entre otras cuestiones que los aspectos significativos propios de las realidades colectivas $\mathrm{y} / \mathrm{o}$ comunitarias de la muerte resulten 'devaluados' $\mathrm{o}$ 'invisibilizados' en esas etnografías.

A pesar de ello, los registros etnográficos de los y las antropólogas muestran referencias importantes relacionadas con:

1) Las prácticas mortuorias relativas al cuerpo del difunto (que incluyen ciertos tabúes socio-culturalmente establecidos) como así también tecnologías diversas para su inhumación además de ciertas formas de manipulación, ofrenda, modos de purificación del cadáver, etc. 
2) Lo relativo a la distribución ritual de alimentos en las ceremonias funerarias; aspecto que además tiene implicaciones simbólicas referidas a la vida sexual (Mircea Eliade, 1997:54-56); aunque en este caso, aparezcan de manera negativa (como 'tabú' de contacto con el cadáver) y, a la vez, acompañadas, muchas veces, de estereotipos de género fácilmente registrables al observar la organización, provisión, cocción, distribución, etc. de los alimentos.

3) Diferentes prescripciones de actitudes y/o conductas relacionadas con el parentesco para los diferentes momentos que recorren los rituales funerarios y el duelo; en las que se entrecruzan componentes religiosos y vivenciales propios del catolicismo y sistemas de creencias originarias que, a veces es difícil, distinguir unas de otras

4) Los aspectos emocionales, imaginarios y simbólicos ligados a la muerte dentro de cada grupo social o "comunidad"; en el contexto de las creencias y de los demás elementos discursivos y prácticos que constituyen su universo de experiencia o lo que algunos autores han denominado, "concepción del mundo". Con referencia a la concepción del mundo, Redfield señalaba que

“...si hay un significado en la (...) concepción del mundo (...) es (...)lo que indica acerca de la estructura de las cosas, tal y como el hombre se percata de ellas (...) es la manera como nos vemos en relación con todo lo demás (...) es una escena montada (...) Lo que hay (en ella) es que es un ordenamiento de las cosas sobre las que se lanza la mirada, cosas que se conciben en primer lugar como existentes (...) maneras en que se conocen característicamente los límites o ilímites (Redfield, R, 1963:107-111).

En este sentido, es importante que la “...concepción del mundo: montaje de la escena de todos y de cada uno" hace referencia a "las experiencias humanas universales (...) el nacimiento, la muerte (y) en el grado mayor de influjo universal (...) la maduración y la senilidad, la menstruación, la menopausia y las relaciones sexuales (y a las) actitudes tomadas ante estos conocimientos inevitables..." (1963: 117-118) 
Esos aspectos de la muerte presentes, con probabilidad verosímil, en la mayor parte de los grupos sociales distintos, estuvieron presentes en las modalidades mortuorias ejecutadas luego del asesinato de Doña Esperanza Nieva, dirigente comunera muy respetada dentro de la comunidad de Amaicha del Valle en la que había sido electa como miembro del Consejo de Ancianos y donde era reconocida, además, como la más conocedora de las hierbas medicinales. No obstante, las prácticas y discursos que dicho asesinato reactivó justifican, a mi entender, el énfasis en el último de los cuatro aspectos señalados como así también, el privilegio de las implicancias que su muerte tuvo en los días y meses que le siguieron; es decir aquellos eventos extraordinarios que se registraron luego de que los rituales funerarios rutinarios en Amaicha del Valle fueron ejecutados.

La relevancia que le adjudico a esos acontecimientos se vincula con ciertos avances de mi investigación en cuyo contexto resultan comprensibles algunas facetas del impacto provocado por la muerte-asesinato de Doña Esperanza; pero los expondré solo brevemente en un apartado mas adelante. ${ }^{2}$

\section{3- La muerte por asesinato de la comunera Doña Esperanza Nieva}

Doña Esperanza Nieva era miembro de la comunidad indígena de Amaicha era madre, coplera, artesana de la cooperativa de artesanos de la comuna rural. Con más de 81 años vivía sola -lo cual es algo común entre las ancianas comuneras- en Los Zazos, a escasos tres kilómetros de la villa de Amaicha. El vivir sola implica, no obstante, estar en las proximidades de otros u otras familiares; en un predio que es amplio y es común a varias viviendas. Era una activa dirigente de la Comunidad Indígena de Amaicha formalizada como asociación sin fines de lucro en los años 90- y, con otros/as, había encabezado su delegación en la Marcha Indígena en Buenos Aires, realizada con ocasión de los festejos del Bicentenario, en el mes de Mayo de 2010. Además, era sanadora, considerada una de las más conocedoras de las hierbas medicinales y curas

\footnotetext{
2 Cuando se produjo el asesinato de Doña Esperanza yo hacía dos meses que no me encontraba en Amaicha; sin embargo, pude recoger referencias de dicha consternación o conmoción entre los comuneros a través de charlas telefónicas con algunos de ellos con los que tengo contacto y a través de las páginas colgadas por la Comunidad Indígena de Amaicha en Internet. Alrededor del 13 de Julio del mismo año regresé a Amaicha donde permanecí alrededor de tres meses.
} 
tradicionales y, atendiendo a todas estas cualidades, podría decirse que no solo reunía todas las condiciones para ser elegida representante de la "Pachamama" en las festividades del mes de febrero, (coincidentes con el Carnaval Andino) sino que las superaba largamente.

Sin embargo, el 8 de junio de 2010 (tan solo trece días después de realizada la Marcha Indígena por el Bicentenario), fue encontrada sin vida en su vivienda por una sobrina. Había muerto el día anterior y su cadáver mostraba rastros de una brutal violencia. La casa desordenada, con una radio con el volumen excesivamente alto y el agua que escurría por debajo de la puerta hacia el exterior fue el primer escenario que precedió el descubrimiento del acontecimiento brutal que conmovería a Amaicha y Los Zazos (que comparten con otros la jurisdicción de la Delegación Comunal de Amaicha del Valle) ya que, estas circunstancias poco usuales, llevó a sus familiares a ingresar en la vivienda.

La policía de la Comuna Rural estableció que la muerte había sido consecuencia de un paro cardio-respiratorio e intimó a la familia a que lavara el cuerpo para su posterior tratamiento en una funeraria de la región. La familia dudó en hacer ese procedimiento de lavado del cadáver pero, ante la evidencia de los brutales golpes en el cuerpo de Doña Esperanza, su hijo que era periodista en Santa María (Catamarca) junto a la Comunidad Indígena de Amaicha, pidió ante la Fiscalía de Monteros (con jurisdicción legal sobre la Comuna Rural de Amaicha del Valle) que le fuera realizada una autopsia cuyo resultado permitió comprobar su muerte por golpes y su violación.

\section{3.a - Las Ceremonias fúnebres tradicionales en Amaicha del Valle}

El velatorio de Doña Esperanza Nieva fue realizado, siguiendo las pautas rituales tradicionales, cuando su cuerpo fue devuelto a Amaicha nuevamente, luego de realizados los procedimientos judiciales y forenses de rutina. Como consecuencia de éstos fue más breve. Congregó, sin embargo, masivamente a comuneras y comuneros que viven en las distintas localidades mas pequeñas que se integran en la Comuna Rural de Amaicha del Valle. Las ceremonias y rituales funerarios en Amaicha del Valle pueden agruparse dentro de las formas conocidas del” velorio" en áreas rurales. Desde 
que se inicia, el espacio destinado en la vivienda familiar para albergar al difunto, es ornado con flores naturales o de papel dispuestas en ramos multicolores que rodean al yacente en un “cajón” o féretro de madera. En el momento posterior a la defunción, la familia, vecinos o amigos muy cercanos comienzan a organizar lo que denominan, la "ranchada" con que se recibirá a quienes concurran a acompañar al difunto y a sus familiares y muy allegados. Las mujeres colaboran con las distintas actividades de la preparación y distribución de los alimentos entre los asistentes, ayudando a los/as que pertenecen a la familia del difunto; especialmente cuando éstos/as son demasiado ancianas/os y se encuentren enfermas/os. De esas actividades participan también los varones; quienes se hacen cargo, además, del asado de carne o elaboración del locro comidas habituales en estas ocasiones- de la provisión de bebidas alcohólicas que deberá ser abundante tanto en cantidad como en variedad. El "velorio" transcurre en medio de expresiones de dolor y de angustia muy controladas, por parte de los mas allegados al difunto/a; quienes muestran una especial preocupación o una actitud muy especulativa por la cocción y distribución de los alimentos entre los asistentes y por la óptima concreción de la misma. La preocupación por la provisión de comidas y bebidas es “...que alcance para todos". Esta es una condición tan importante que suele solaparse, de modo significativo, con las expresiones, mas profundas e íntimas, ligadas con el respeto y las demostraciones de dolor que se le debe al/la difunto/a; lo cual justifica la minuciosidad y la prolijidad con que dicha provisión se realiza; a pesar de la tristeza y la angustia que normalmente embargan a los deudos.

Los asistentes, por su parte, aportan, a veces, comida (carne de chivo, de vaca, de cordero, locro, empanadas, etc.) y también bebidas. Es común que el "velorio" dure entre dos y cuatro días, durante los cuales en una mesa habitualmente ubicada en el patio de la vivienda se bebe y se come, se cuentan chismes, y algún chiste; se evocan anécdotas del difunto o de la difunta, se lo recuerda con signos de dolor, etc.; todo esto sin acompañamiento musical ya que en el "velorio" amaicheño ni siquiera la copla tiene lugar. Dos momentos son especialmente dramáticos para los deudos ( familiares, compadres, comadres y amigos): el inmediato a la defunción; lo cual habitualmente se produce en el domicilio (o en caso de no acaecer en éste, el del arribo del cuerpo desde el lugar de la defunción) y el del entierro que se realiza luego de una breve misa de 
cuerpo presente en la Parroquia San Ramón Nonato que es la única en el área abarcada por la Comuna Rural. En el curso del entierro, especialmente, las expresiones de angustia y de dolor se manifiestan más abiertamente, en contraste con las actitudes o conductas características de la organización del "velorio", su transcurso y la "ranchada" que lo acompaña. Por último, a partir del día siguiente de la muerte se realizan las "novenas" consistentes en nueve noches consecutivas de rezos del rosario que realizan los familiares y vecinos más próximos, los compadres y las comadres y amigos/as del/a difunto/a para pedir por el bienestar de su alma. Por fin, el décimo día se realiza una misa que se le dedica al difunto /a con lo que concluye el ciclo de ritualización formal amaicheño de la muerte. De este modo, la comunidad amaicheña no se distingue demasiado de los modos característicos con que otras comunidades rurales de América Latina ejecutan sus rituales de la muerte, aunque tienen, no obstante, sus especificidades locales. Robert Redfield (1941) quién, en su investigación sobre Yucatán, insistía en las diferencias entre las cuatro comunidades estudiadas (Mérida, Dtizas, Chan Kom y Tusik; la primera una ciudad y el último un conjunto tribal) afirmaba, sin embargo, la existencia de fuertes similitudes en cuanto al amortajamiento de los muertos para su inhumación y los rituales que se siguen a ésta como así también que esto podía deberse a la influencia de la colonización religiosa española sobre América Latina (R. Redfield; 1941); que se inicia a mediados del siglo XVI en los Valles Calchaquíes y de la que se sabe por estudios etno-históricos que fue temprana e intensa en el Valle de Amaicha (Cruz, R, 1997).

El entierro de Doña Esperanza en el cementerio local fue “...el mediodía de este jueves tan perramente frio y gris, (su cuerpo) miraba hacia el sur, en la parte sur del cementerio, en fin, que no era algo así nomás, e iba a traernos muchos mas interrogantes..." (Siga, 2010). Jorge Siga, escritor y comunero por alianza, residente en Amaicha desde hace años, en su "semblanza" de Doña Esperanza escrita el 14/6/2010 exponía algunos de los comentarios que recorrían la villa en esos días, anticipando, además, algunas de las cuestiones que yo registraría después, entre 2009 y 2010 y entre 2014 y 2018, sobre esta muerte que adquirió una repercusión singular dentro de la comunidad amaicheña.

Como ha señalado Renato Rosaldo 
“... las etnografias escritas según las normas clásicas consideran a la muerte como un ritual en vez de una desdicha (...) El ritual en si se define por su formalidad y rutina, bajo dichas prescripciones mas bien se parece a una receta, un programa fijo (...) que un proceso humano abierto." (Rosaldo; 1991: 24)

Este enfoque de la muerte es, para Rosaldo, algo que "Encubre la fuerza emocional de la aflicción, reduciendo el ritual funerario a una rutina de orden..." mientras que, en realidad, "...los seres humanos se duelen tanto en escenas rituales como en marcos informales de la vida cotidiana..." (1991: 25).

Su énfasis en considerar “...al ritual como un proceso autónomo infinito..." que posee, no obstante, limites definidos que deben ser considerados; es de gran importancia para comprender las características de la consternación, la producción de explicaciones del sentido común y de la movilización colectiva que siguió a la muerte de Doña Esperanza. Si el ritual puede considerarse como "una intersección transitada..." en el que se vinculan “...un número de procesos sociales distintos...” y sus encrucijadas brindan un espacio en donde "...recorrer distintas trayectorias." de procesos que "...ocurren antes o después de su realización" (1991:30-31); los eventos que ocurrieron tras el asesinato de Doña Esperanza Nievas bajo la forma de consternación y de movilización colectiva parecen enfatizar un punto de una trayectoria comunitaria muy significativa que relacionaría a la muerte, al género y a la comunidad dentro del contexto identitario socio-cultural de los amaicheños/as. Su muerte dramática permite acotar y especificar los límites del ritual así como su relación con la vida cotidiana y con las problemáticas que acucian a la comunidad.

\section{3.b - Ritual, Género y Comunidad en Amaicha del Valle.}

Cuando el cuerpo de Doña Esperanza Nievas fue sepultado en el cementerio local, el 10 de Junio de 2010; los comuneros ya se hallaban sumidos en una profunda conmoción que ponía de manifiesto una faceta inusitada de la significación de la muerte en Amaicha. Ésta parece mucho mas poderosa que la descripción de los rituales y 
ceremonias, usos y creencias tradicionales ligados con la muerte. Dicha significación, no obstante, solo es comprensible en el contexto de las modalidades comunitarias de constitución grupal e identitaria amaicheña.

La cuestión del 'territorio' es un aspecto clave en los clásicos estudios sobre comunidades en Antropología (Redfield, Foster, Wolf, etc.). Especialmente, aquellos que están centrados, en lo que se ha dado en llamar 'comunidades rurales $y / o$ campesinas tradicionales', de marcado carácter indígena-criollo, en contraposición, con lo que mas recientemente se ha dado en llamar, "comunidades post-societales", en tanto que agregados de personas que se agrupan por propia voluntad y que no necesariamente son permanentes o estables como las primeras. (de Marinis, Pablo, 2005 :27).

Por su parte, Erik Wolf ha señalado el carácter de construcción hispana que poseerían las comunidades indígenas latinoamericanas ya que la estructura comunitaria no sería originaria (precolombina) si no que habrían sido impuestas como un mecanismo de control de las poblaciones conquistadas. Las mismas, estando constituidas por instituciones 'locales' propias y una personalidad moral (político-religiosa; el Derecho Mayor), permitían a los conquistadores españoles contar con unidades territoriales básicas para percibir el tributo y los servicios personales a que eran obligados los indígenas. Recientemente. Alejandro Isla ha sugerido un vínculo entre "comunidad y territorio" al señalar los aspectos imaginarios relativos al reconocimiento de la posesión comunitaria de la tierra concedida a los amaicheños/as por una Merced Real en 1716; los cuales serían fundamentales para la construcción de “...una memoria de identidad (...) que permite generar los límites de un 'nosotros",' (Isla, A; 2005:4) comunitario.

En mi perspectiva de género, el carácter emblemático de ese documento no sintetiza, sin embargo, la totalidad de los elementos simbólicos e imaginarios puestos en juego en el proceso de producción de una identidad al interior de la comunidad de los amaicheños/as. Los enfoques de Françoise Herittier $(1977,1989)$ sobre la formación de la persona samo (África) y de Anne Chapman sobre la ceremonia del Hain, entre los Selk'nam (Tierra del fuego) permiten considerar el 'carácter territorializado' de las prácticas de los hombres y las mujeres en las configuraciones comunitarias, especialmente aquellas de fuerte componente originario, que se actualizarían en distintos contextos rituales y/o ceremoniales de las mismas. Éstas habrían preexistido a 
las administraciones coloniales prehispánicas e hispánicas bajo formas muy distintas de las que se presentan en las diversas articulaciones políticas, incluso las originarias con objetivos de legitimación.

Estos son aspectos teóricos que recoge, en líneas generales, mi investigación de campo en Amaicha del Valle y que parecen claves para comprender los efectos que la muerte de Doña Esperanza Nieva tuvo en dicha comunidad. Me parece necesario una consideración sumaria de algunos de los aspectos relacionados con "...la existencia de una "territorialidad simbólica de género" que parece ser tributaria de la construcción de una identidad comunitaria entre los amaicheños..." (López Machado, 2010b) para poder comprender el impacto de la defunción por asesinato de la anciana comunera, Doña Esperanza Nieva.

En este sentido cabe considerar lo señalado por Edwin Ardener en su volumen "Belief and the problem of women y The problema revisited", , que fuera editado por la antropóloga Shirley Ardener, su esposa en su libro Perceiving Women En el mismo, Edwing Ardener, profesor visitante en una Cátedra de Antropología Social de Oxford, por invitación de E.E Evans Pritchard, ha dado lugar a la formulación de una Teoría de los Grupos Silenciados que ha sido reelaborada, según diversas ópticas por varias antropólogas feministas; entre ellas Henrietta Moore (1991). En líneas generales, Ardener plantea que existen un conjunto de categorías de personas (gitanos, delincuentes, niños, mujeres, etc.) a los que no les es posible expresar sus visiones del mundo por fuera del discurso dominante que es hegemónico y androcéntrico y que no los expresa del todo. En el caso de las mujeres esta dificultad opera con mayor fuerza ya que ellas están condenadas al "Silencio", son silencio social. No es que las mujeres no hablen; sino que sus palabras no tienen inscripción en el discurso dominante masculino que es el de la norma patrilineal y lo público- político de los grupos y sus específicas estructuras lingüísticas. Habiendo investigado en Camerún, Ardener plantea -como aspecto importante de su Teoría de los Grupos Silenciados- una fuerte impronta androcéntrica en la Antropología puesto que los modelos elaborados por antropólogos varones son fácilmente comprensibles dentro de la Antropología que, a través de sus informes etnográficos, impone una visión del mundo masculina. Los grupos silenciados, cuyas voces quedan "amortiguadas” (Moore,1991), logran cierta expresión a través de 
las formas discursivas masculinas y hegemónicas. Pero esto no ocurre con las mujeres, quienes no pueden expresar su "visión del mundo" en los mismos términos de los modelos masculinos hegemónicos. Las mujeres no pueden darle cuerpo a su visión específica a través de las estructuras discursivas masculinas; simplemente por el hecho de que los hombres y las mujeres tienen "distintas visiones del mundo" "distintos modelos" (Ardener, 1968, 1975 y 2006; Moore; 1991).

Por último, lo más importante -en función de la temática que trato en este trabajo- es que Ardener planteará que tanto las y los antropólogas/os comparten estos modelos propios de disciplinas orientadas hacia los hombres y sus problemas. Entre ellas, la Antropología dado que quienes la ejercen, ya sean hombres o mujeres, implementan los modelos masculinos de la propia cultura para interpretar visiones masculinas de otras. Significativamente resulta haber afinidades entre las visiones masculinas de los y las investigadores/as; quedando de inmediato excluidas las visiones de las mujeres informantes. (Ardener, 1968,1975 y 2006; Moore, 1991). Esto es relevante por el tipo de referencias etnográficas en que se sustenta mi trabajo de campo y el tipo de interpretación que realizo con relación a las repercusiones del Género en la formación de una matriz comunitaria e identitaria de la comunidad indígena de Amaicha, de la que Doña Esperanza formaba parte activa, habiendo sido brutalmente asesinada al interior de la misma.

\section{4 - La categoría analítica de territorialidad simbólica de Género}

Desde comienzos de mi trabajo de campo en la Comuna Rural, tres aspectos fueron considerados como significativos de la dinámica cotidiana de la villa: los desplazamientos territoriales en Amaicha del Valle de hombres y mujeres, las modalidades de conformación de muchas familias comuneras y un conjunto de prescripciones creencias relativas a los desplazamientos territoriales de las mujeres cuando menstrúan. Éstos, dan cuenta de una territorialidad acotada al dominio en que los grupos familiares y sus miembros, varones y mujeres, desarrollan sus actividades cotidianas; extendiéndose la mayoría de ellos, habitualmente, hasta donde realizan la provisión de recursos naturales tales como la leña para su subsistencia, piedras, hierbas 
aromáticas y distintos elementos para realizar tinturas textiles en el caso de las tejedoras, y, por otra parte, a las redes de su sociabilidad.

En líneas generales, dichos desplazamientos parecen ligados, indisociablemente a las atribuciones y funciones que es posible suponer que son las pre- establecidas para hombres y mujeres dentro de la comunidad. Sin embargo, la muy usada distinción entre "actividades reproductivas femeninas" y "actividades productivas masculinas" no es significativa, ya que es relativa, para comprender esa modalidad territorial, puesto que en el ámbito doméstico, que se superpone relativamente al de la vivienda familiar- todas estas actividades son, en líneas generales, desarrolladas, a veces -alternadamente o simultáneamente- por hombres y mujeres.

Lo que parece caracterizar la territorialidad de los amaicheños/as es la "frecuencia cualitativa" de dos tipos de desplazamientos diferenciados: a) por una parte, los que afectan a las mujeres y que se producen, rutinariamente en el interior de la villa o en las inmediaciones más próximas de ésta y, b) por la otra, los que afectan a los hombres que se diferencian de los femeninos, no tanto, por una mayor extensión en el espacio físico sino mas bien por una ampliación y diversificación de las fronteras territoriales femeninas en beneficio de una sociabilidad que supone una permanencia en los espacios concretos mas restringida.

De este modo, la territorialidad de los amaicheños/as parece establecerse a partir de una oposición que afecta -antes que nada- una oposición simbólica entre dos ejes espaciales "periférico-externo-masculino/central-interno-femenino" con el cual parecen ligarse distintas dimensiones relacionales muy marcadamente notorias en la observación participativa en la vida cotidiana de los miembros de la comunidad indígena.

- Por una parte, una forma de constitución familiar bastante frecuente que une, como elemento estable de las familias, a mujeres de dos o más generaciones que cohabitan con sus hijos hasta que éstos forman una pareja. Los hombres son el elemento móvil de estas "asociaciones familiares" que se consolidan, a veces, sobre la base de los lazos parentales femeninos primarios (consanguinidad directa) ya que si forman pareja o se casan, pasan a vivir con los padres de la mujer; regresando al hogar materno si la pareja o el matrimonio se deshace; siendo éste un aspecto decisivo para interpretar la 
modalidad simbólica que registramos en esos desplazamientos femeninos; que constituirían, contrastados con los masculinos a "la territorialidad simbólica como una estructura social de género".

- Por otra parte, en el interior de los hogares amaicheños sostenidos, muchas veces, por cadenas generacionales de mujeres emparentadas por línea consanguínea se preservan actualmente las actividades tradicionales y los rituales que aún se realizan y, entre ellos, los mortuorios o funerarios como así también aquellos que implica la Ceremonia Anual de Ofrenda a la Pachamama, entre la noche del 31 de Julio y el $1^{\circ}$ de Agosto.

- En otro extremo, el de lo masculino, una de las formas características de sociabilidad entre los varones en Amaicha es el "compadrazgo". Con relación a este tipo de institución social, Foster ha señalado que conviene distinguir entre una conducta ideal y una conducta real en ella ya que una descripción puramente formal de ésta da poca idea de cómo opera el sistema (Foster, 1974). Por su parte, M.N Chamoux (1980) ha señalado el uso que se hace del término 'compadre' en situaciones no convencionales; a saber, entre compañeros de copas, lo cual es muy frecuente en Amaicha del Valle con respecto a ciertas relaciones entre varones que se tratan como 'compadres' sin serlo formalmente; aunque, no obstante tienen bastante estabilidad y continuidad temporal. Aquí lo importante no sería tanto el consumo de alcohol sino las formas de sociabilidad amplificada que esas relaciones entre compadres habilitan. Estas modalidades no convencionales, que pueden ser interpretadas como expresiones no clásicas de "compadrazgo" (López Machado 2010) y podrían dar cuenta de una contrapartida en las 'cadenas familiares femeninas'; conforman un dominio en cuya intersección se constituye un interesante campo para un estudio antropológico de la muerte en Amaicha del Valle, puesto que afectan al núcleo mas íntimo y menos explícito de su identidad comunitaria vinculada, en mi enfoque, a una "territorialidad simbólica de género".

En este artículo no consideraré el aspecto de las prescripciones y creencias acerca de la conducta que deben seguir las mujeres cuando están menstruando, que hemos considerado en otros trabajos. Éste y los anteriormente señalados permiten de modo sumario señalar la importancia de la "territorialidad simbólica de género", como 
categoría analítica básica que no refiere a los desplazamientos reales de hombres y mujeres; los cuales son, por lo demás, muy variados en diversos sentidos. A partir de estos dos ejes conceptuales, intento aproximarme a las especificidades de la Comunidad Indígena de Amaicha, a sus formas de ocupación y uso territorial, fuertemente investidos de un valor simbólico que es eficaz para la actualización y continuidad de formas de concepción igualmente ancestrales.

La razón del privilegio de esta "territorialidad" amaicheña obedece a que permite abordar la perspectiva de los/las comuneros/as mediante la consideración de un espacio social específico que se constituye históricamente en una "encrucijada simbólica de espacio-tiempo" -difícilmente disociables- que articulan las prácticas de los miembros de la comunidad.

\section{5 - Impacto emocional y Movilización colectiva en Amaicha del Valle}

Si bien en la Comuna Rural de Amaicha del Valle existen casos de asesinato (incluyendo un feminicidio brutal y casi público) y otros rotulados como "muerte dudosa"; la conmoción que circunscribió los rituales funerarios -dedicados a la memoria y al pedido de Justicia para la anciana comunera asesinada- dio lugar a una importante movilización colectiva que se proyectó hasta varios meses después de producida su inhumación. Aunque las propias características del crimen (asesinato y violación de una anciana) justifican, en gran medida, ese impacto; la intensidad y la modalidad que adquirió para los miembros de la comunidad indígena, su repudio y denuncia, tienen una potencia y una especificidad incontestables que afecta distintos ordenes de la cotidianeidad comunitaria ${ }^{3}$.

Uno de los hechos más significativos, con referencia a ello, es que esa movilización se produjo en un contexto signado por un tono emocional y/o afectivo muy intenso. Más o

3 En los meses subsecuentes se supo que había varios sospechosos comuneros de nacimiento de identidad desconocida que habían sido objeto de estudios de ADN. De ellos se rumorea que dos se habrían fugado; aunque ésta es solo una más de las versiones explicativas de los hechos y hasta donde sé no hay pruebas efectivas de que así sea. Cabe considerar, asimismo, que si bien en los primeros días siguientes al asesinato se prometió que habría una Comisión Investigadora con sede permanente en la Comuna Rural de Amaicha del Valle esto nunca ocurrió. El Instituto Nacional Indigenista es una institución que ha permanecido ausente frente a estos hechos que tienen una dimensión política, social y humanitaria inapelables. Al día de hoy (Octubre 
menos predispuestos a hablar sobre los hechos -y a dar detalles-distintos miembros de la Comuna Rural -comuneros/as o criollos/as- tendían a una explicación de los mismos en términos de una transformación negativa, de un cambio inminente e irreversible en las rutinas cotidianas de la Comuna Rural. Fue evidente que todos, en algún momento, se orientaron hacia consideraciones de que “... algo cambió...algo se perdió para siempre...". ${ }^{4}$ Los sectores más tradicionales u ortodoxos de la vida comunitaria no se privaron de culpar a "los hippies esos, que vienen con la droga y malas costumbres". Los llamados “ hippies” son gente que, ha decidido vivir en la Comuna Rural, a pesar de los importantes prejuicios que pesan sobre ellos. Suelen ser gente tranquila, dedicada a las artesanías y bastante respetuosa de las demás personas que los estigmatiza. Los argumentos; las versiones circulaban, como es evidente, de modo caótico y lo que predominaba, explícita e implícitamente, era la idea de que “...ya nada volverá a ser como era...".

Por otra parte, la misma noche del día en que se descubrió cadáver de Doña Esperanza muchas mujeres se reunieron frente a la comisaria para tomarla. En los días subsiguientes se realizaron numerosos cortes de ruta, marchas entre los Zazos y la villa de Amaicha, denuncias periodísticas, reclamos ante las autoridades provinciales y nacionales; la mayor parte de ellos protagonizados y conducidos, principalmente, por mujeres de la comunidad (comuneras) que se organizaban, discutían, evocaban, lamentaban la ausencia de Doña Esperanza. Muchas de ellas no eran militantes activas de la comunidad hasta que se produjo esta muerte y es, por la confrontación permanente que generó, que la muerte de la comunera parecía actualizarse cotidianamente; volviendo a poner 'sobre el tapete' valores comunitarios tradicionales que coagulaban identitariamente, de modo particular, en torno a estos hechos.

Por su parte, las discrepancias entre las distintas "facciones" (como las denominaba Alejandro Isla (2005) o 'pugnas políticas internas' existentes al interior de la Comunidad y la Comuna -que se disputan el poder de mantener relaciones con el Estado

\footnotetext{
${ }^{4}$ Todos los destacados en negrita son míos y corresponden a información proveniente del registro oral en mi investigación
} 
nacional y provincial, mediante la gestión y el Gobierno de la Delegación Comunal provincial y/o el cacicazgo de la Comunidad Indígena- se habían exacerbado, al punto de llegar a culparse entre los y las miembros de cada una de ellas del asesinato de la comunera; aunque las versiones y los argumentos variados que circularon, caóticamente, se articulaban en torno a una sensación casi generalizada de que en Amaicha se había producido una transformación profunda como consecuencia, entre otras, de las actividades criminales de “...gente de afuera...que viene de otro lado...”; sin demasiadas precisiones alrededor de quienes eran estos 'extraños' ni de cuales serían sus objetivos al ejecutar el asesinato de Doña Esperanza.

En la segunda quincena de Julio, cuarenta y cinco días después de la inhumación de la anciana, regresé a la villa para permanecer, aproximadamente, tres meses en ella. En esa ocasión, pude percibir un cambio evidente en su dinámica interaccional cotidiana y en el estado de ánimo de sus habitantes. Había en ella una quietud desconocida, a pesar que se preparaba y esperaba la ceremonia de la Ofrenda a la Pachamama, del día 1 de Agosto. Una carencia en la vivacidad habitual en la vida cotidiana amaicheña; entremezclada con una sensación de temor y reserva que, solapadamente, se manifestaba en las conversaciones que abordaban indirectamente o esquivaban, de manera categórica, la referencia al asesinato feminicida y violación de la anciana.

6 - El horizonte comunitario, la muerte por feminicidio y sus ritualizaciones: una perspectiva de las eficacias del género.

En un rastreo de los distintos registros en que puede expresarse la noción de “comunidad" en la obra de Weber -como relato histórico, como tipo ideal de relaciones sociales y como artefacto político histórico- Pablo de Marinis considera que es factible que, en la esfera política, ciertas 'realidades excepcionales' produzcan un recalentamiento de los lazos sociales comunitarios, aún en contextos abiertos por una racionalización y un desencantamiento del mundo (2010). Aunque esta cuestión es tomada en función de la vinculación intrínseca entre guerra, violencia y comunidad política, en su contexto “...la seriedad de la muerte se introduce aquí eventualmente con el fin de proteger (...) los intereses de la comunidad..." (2010:23); lo cual produce una "comunización emotiva" (2010: 26). 
Pablo de Marinis nos habla, en ese texto, de dos conceptos socio-políticos nodales en Weber "la comunidad de los combatientes" (en el campo de batalla) y la comunidad producida por “...la Democracia Plesbicitaria del Lider Carismático”; situaciones que no pueden reducirse fácilmente en la interpretación del impacto causado por el asesinato de Doña Esperanza y sus consecuencias; pero que, sin embargo, son sugerentes para comprender tanto el impacto emocional que ésta produjo como la intensificada movilización comunitaria -mayoritariamente de mujeres comuneras- a que dio lugar.

Si bien, es el asesinato y la violación de una anciana comunera la que dio lugar a esas consecuencias y no la guerra, puede considerarse que Doña Esperanza era una líder de su comunidad y, por ello, un referente de los valores tradicionales muy arraigados y, a partir de ello, puede evaluarse que las características sombrías de su muerte deben haber puesto profundamente en 'entre dicho' la articulación comunitaria y las perspectivas de su continuidad por lo menos en el plano de los imaginarios. Es por ello, que cabe considerar lo que de Marinis afirma con relación a las situaciones abordadas por Weber; que "el ejercicio de dar sentido está existencial e individualmente anclado pero permite constituir colectividades de carácter totalizante en las que se rompen los límites del yo" (2010:26) y que esto adquiere, muchas veces, la forma de una 'comunización' fuertemente emotiva.

Por su parte, Ramos Torres señala que para Durkheim el vinculo comunitario, originalmente ligado a lo sagrado, y sus representaciones (dioses, emblemas, etc.)

“...vienen de la práctica, no son mas que práctica objetivada, simbolizada y relatada (...) esa acción es comunitaria (...) El punto de partida es el encuentro preverbal y cargado emocionalmente que se repite una y otra vez (...) es un encuentro de los cuerpos (...) esta experiencia está cargada emocionalmente, provoca una (...) auto-trascendencia (...) lo que Durkheim llama los 'medios sociales efervescentes' que se describen y analizan de la mano de la metáfora fundante que asimila el espacio social a un campo de fuerzas" (Ramos Torres, 2010: 398-400) 
Ambas conceptualizaciones son significativas para considerar como un hecho antropológico la movilización colectiva que circunscribió el asesinato-feminicidio y violación de Doña Esperanza y, nos permiten retomar lo relativo a la acción de las mujeres como un aspecto que, en gran medida, caracterizó la misma.

Según Ramos Torres, de

“...esta socialidad básica de la comunidad emergen sentimientos que se plasman en ideales que fijan valores comunes del grupo y sus metas colectivas de acción” (2010:399); agregando que esta comunidad fundante “...es efimera queda expuesta a un tiempo que la devora (...) está destinada a perder progresivamente su energía primera...” por lo que requiere “...ser reactualizada periódicamente. $Y$ es aquí donde parecen los grandes mecanismos de preservación, reconstitución, realimentación de la comunidad: los rituales (...) rito y comunidad son las dos caras de la misma realidad." (2010:400)

Es, en esta perspectiva, donde la muerte de Doña Esperanza Nieva, trascendiendo; o bien, llenando de contenido el concepto de "feminicidio" y sus efectos -dentro de la comunidad indígena-- parecen adquirir una dimensión conceptual de gran significación que podría permitir a) por una parte, articular la relación entre ritual y vida diaria (o cotidiana) señalado por Rosaldo (1991) y b) por otra, reforzar la idea de que esa identidad comunitaria está fuertemente marcada en su especificidad por oposiciones territorializadas como "periférico-externo-masculino" y "central-internofemenino" cristalizadas a partir de una "territorialidad simbólica de género" que 
serviría de soporte a la producción de una identidad comunitaria de los amaicheños/as. Como señalara en un trabajo reciente

"Al interior de este complejo contexto referencial, el privilegio de las distinciones de género - a las que defino como una "producción socio-cultural de estereotipos especiales de sexualidad" (López Machado; 2004,2006-2010)además de representar un interés teórico personal-se imponen como un aspecto clave para el reconocimiento de (...) un núcleo ideológico y práctico de suma importancia para aproximarnos a la matriz comunitaria e identitaria de esa comunidad indígena.” (López Machado, 2018)

y comprender en ese marco interpretativo las significativas expresiones de conmoción que. produjo la muerte por asesinato-feminicidio de la anciana comunera. Esta conmoción comunitaria fue acotada a un tiempo relativamente breve, pero intenso que interpreto como una activación de las estrategias ritualizadas de la comunidad, sin precedentes desde 2007 en que realizo mi investigación en la comunidad.

Si bien, desde el punto de vista político comunitario, la Comunidad Indígena de Amaicha -constituida por un cacique y un Consejo de Ancianos (que está integrado por algunas mujeres; Doña Esperanza lo integraba, al momento de su muerte)- tiene un papel público denunciante y querellante respecto del esclarecimiento del asesinato de Doña Esperanza (del que actualmente casi no se habla); tanto en la esfera local como en la regional y provincial; las mujeres estuvieron, en los primeros meses en que éste se produjo, particularmente activas y comprometidas en esa lucha. Fueron ellas quienes masivamente se reunieron frente a la Comisaría para tomarla y pedir las renuncias de las autoridades; fueron las comuneras quienes encabezaron los cortes de ruta y las marchas que se realizaban los días lunes desde Los Zazos a Amaicha; marchando, luego, alrededor de la plaza principal de ésta. Por todas estas acciones, se transformaron, por un tiempo, en las más legítimas responsables por el esclarecimiento de ese hecho que conmovió, particularmente, a la comunidad y, por ello, en las mas firmes exponentes de 
una participación política comunitaria, de carácter fuertemente colectivo, pocas veces vista en Amaicha del Valle.

En el interior de la villa fueron ellas las principales encargadas de mantener la vigencia del reclamo y de evocar en sus habilidades de artesana, coplera, sanadora, madre, indígena, “...defensora de nuestros derechos...”. De algún modo, toda la "sensación de pérdida, confusión y desazón" -que conmocionó a la Comunidad Indígena y a la Comuna Rural de Amaicha del Valle- parecía encarnar en ellas, a través del activismo comunitario: salían de sus hogares, se reunían, discutían, planificaban, traían a la memoria a Doña Esperanza; organizaban y se las veía ocupando los lugares públicos y estableciendo redes de sociabilidad que anteriormente habíamos relacionado con los desplazamientos masculinos y con 'formas no convencionales de compadrazgo'. Los hombres conmocionados también se movilizaron; pero, al parecer, tenían un especial reconocimiento del derecho y la legitimidad de que ellas fueran, las artífices de esa importante protesta colectiva por el esclarecimiento del asesinato. Una de las características principales de la misma fue que no la realizaron desde un lugar "victimizado", sino con enérgica convicción sobre sus derechos comunitarios y, por supuesto, los de la anciana que -con el asesinato-feminicidio- habían sido cruelmente y definitivamente vulnerados, al punto de haber sido sometida a la violencia y la humillación de unos, hasta hoy, "presuntos culpables", quienes, además aún no están siendo juzgados en los Tribunales de la jurisdicción.

Rita Segato -en su teoría de carácter fuertemente totalizador y sistematizador de la significación del género y sus relaciones- señala que “...mi convicción de que el patriarcado, o relación de género basada en la desigualdad, es la estructura política más arcaica y permanente de la humanidad.(...) una estructura que moldea las relaciones entre posiciones en toda configuración de diferencial de prestigio y de

5 En los meses subsecuentes se supo que había varios sospechosos comuneros de nacimiento de identidad desconocida que habían sido objeto de estudios de ADN. De ellos se rumorea que dos se habrían fugado; aunque ésta es solo una más de las versiones explicativas de los hechos y hasta donde sé no hay pruebas efectivas de que así sea. Cabe considerar, asimismo, que si bien en los primeros días siguientes al asesinato se prometió que habría una Comisión Investigadora con sede permanente en la Comuna Rural de Amaicha del Valle esto nunca ocurrió. El Instituto Nacional Indigenista es una institución que ha permanecido ausente frente a estos hechos que tienen una dimensión política, social y humanitaria inapelables. Al día de hoy (Octubre de 2017) no se ha realizado el Juicio por el feminicidio y violación de Doña Esperanza. 
poder” (Segato, 2016:18).El patriarcado es descripto como “...este cristal arcaico, de tiempo lentísimo a pesar de plenamente histórico, con la expresión prehistoria patriarcal de la humanidad (Segato, 2003) Sustenta mi afirmación de su precedencia y universalidad la constatación de la existencia de una formula mítica, de dispersión planetaria que relata un momento ciertamente histórico (...) en que la mujer es vencida, dominada y disciplinada" (2016:19). A este planteo agrega que "La expresión patriarcal-colonial-modernidad describe adecuadamente la prioridad del patriarcado como apropiador del cuerpo de las mujeres como primera colonia" (2016:19) Este sería un posible punto de partida para la interpretación del asesinato-feminicidio; pero, desde mi punto de vista, su generalidad lo torna inadecuado para comprender este caso. Según lo expuesto anteriormente respecto del androcentrismo de la Antropología (Ardener, 1968,1975, 2006; Moore, 1991) las afirmaciones de Segato parecen incurrir en la reserva señalada por este autor acerca de que los y las antropólogos aplican categorías occidentales al conjunto de los diversos grupos sociales. Esto representa, desde mi punto de vista, un aspecto muy potente para entender tanto teórica como metodológicamente, no solo la percepción que existió por parte de la comunidad sobre la muerte cruel de Doña Esperanza sino también sobre las maneras en que impactó en ella, como así también la magnitud de sus efectos y respuestas.

Por mi parte considerar que una narración vigente sobre los orígenes de los hechos sociales; al igual que la idea de que un relato histórico, "por su hondura temporal ha compactado (...) una sintesis mítica" (Segato, 2016: 19) me resulta discutible, poco convincente y hasta se asemeja a una "naturalización ingenua". No obstante, con relación a la falta de enjuiciamiento de los presuntos autores del brutal crimen contra Doña Esperanza, resulta sugerente su idea de que como consecuencia de una "mecánica de minorización en la estructura binaria de la modernidad (...)" puede ocurrir que “...los crímenes contra las mujeres y la posición de las mujeres en el imaginario patriarcal-colonial-modernidad no acaban de encontrar su justo lugar en el Derecho, ni alcanzan su pleno carácter público jamás" (Segato, 2016:23)

6 - A modo de reflexión 
En líneas generales, lo señalado por Rosaldo con respecto a que "la mayoría de los etnógrafos prefieren estudiar eventos que tienen espacios definidos, con centros marcados y orillas limitadas (pues) sus cualidades de definición fija liberan a dichos eventos del desorden de la vida diaria, de modo que puedan leerse (...) como textos (1991:24) nos ha parecido de interés tomar la movilización colectiva como cierto tipo de ritual que “...actúan como catalizadores que precipitan procesos cuya exposición ocurre en meses subsecuentes..." (Rosaldo, 1991:27).

Bajo la óptica de esta noción del ritual como “...un lugar en que se intersectan un número de procesos sociales distintos...” y en él que las “...encrucijadas solo proporcionan un espacio para recorrer trayectorias en vez de una encapsulación total" (1991:28); la movilización colectiva y el fuerte componente emocional de que se vio investido el asesinato de Doña Esperanza, su muerte cruel parece adecuarse a un esquema analítico de este tipo. Se trataría, entonces de un evento extraordinario, crítico, que se prolongó en un tiempo excepcional -distinto que el de un ritual formal, repetitivo- y que, sin embargo, tuvo la propiedad de realizar, mediante la inversión de los espacios simbólicamente atribuidos -simultáneamente activo en paralelo a las prácticas concretas de los hombres y las mujeres- de la oposición "periférico-externomasculino/central-interno- femenino" 6 que parece exponer, estructuralmente las significaciones que hemos recogido en la categoría analítica de "territorialidad simbólica de género" como tributaria de una identidad comunitaria de los amaicheños/as.

Frente a lo que de Marinis destaca como “...una proliferación de motivos comunitarios en la actualidad", distingue dos "formatos" diferentes de creación comunitaria: uno “desde arriba (...) el mejor recurso que usan los gestores (...) estatales cuando la sociedad..." se presenta a la esfera de la autoridad estatal “...como un territorio demasiado extenso, ingobernable y oneroso..." y otro sería el de las comunidades

\footnotetext{
${ }^{6}$ Esta oposición simbólica se encuentra ritualizada a lo largo de la Ceremonia de Ofrenda a la Pachamama del 1 de agosto de manera evidente y se articula principalmente en la relación del pozo cavado en la tierra en que se introducen los productos ofrendados, precisamente en él. También con la Topada de las comadres, coincidente con el Carnaval andino y con un conjunto de creencias con que se prescribe a las mujeres cuando menstrúan, que ya he analizado en otros trabajos.
} 
“desde abajo" (...) la formula desde la que se enarbolan reivindicaciones (...) cursos de acción..." construyéndose a través de ellas " referencias identitarias". Insiste en que ambos "formatos no se mantienen en estado puro..." sino que aparecen "entrelazados" reconvirtiéndose, tensionándose o apoyándose uno en el otro (de Marinis, P. ;2010:28). Sin embargo, nuestro enfoque específico de la muerte por asesinato-feminicidio de una anciana comunera muestra como aún pueden registrarse otros aspectos de orden simbólico y colectivo que actúan delineando el perfil de una comunidad indígena y rural por sus características geo-políticas -si no especialmente económicas-; que evidencian cómo la muerte bajo ciertas condiciones puede desplegar recursos de orden colectivo ritualizados que son mucho mas ricos que los repetitivos y rutinarios ritos mortuorios convencionales en que redundan algunos (sino muchos) registros etnográficos ya que nos ponen al margen de las implicaciones del carácter emocional, "encarnado”, de toda formación comunitaria.

Si tenemos en cuenta que la comunidad indígena de Amaicha se halla, desde hace varias décadas, expuesta a un abandono acelerado de las formas productivas y artesanales tradicionales -iniciado y llevado a cabo, paulatinamente, hace varios siglos y, también, a presiones políticas estatales y de mercado muy fuertes y si consideramos, además, las consecuencias que esto tiene para sus actualizaciones identitarias, es posible repensar un sentido antropológico de la muerte de Doña Esperanza Nieva mucho mas significativo para una investigación de esa comunidad que la mera descripción de los ritos y ceremonias funerarios que se ejecutan en la mismas. Con ello, se posibilita interpretar porque la muerte de esta anciana comunera 'ha conmovido' a la 'comunidad amaicheña" hasta el extremo de mantenerla significante; aún cuando ya se han efectuado los rituales necesarios que ella prescribe; sumergiéndola en una profunda "sensación de perdida."

Todos estos son aspectos relevantes, registrables solo en la medida que se comprenda que lo relativo a esta muerte, dentro de esta comunidad es una forma de “...intervención colectiva..." que tiende, como toda forma de intervención humana, a “... asegurar la existencia del grupo como grupo y (...) sustituir, en este dominio, como en todos los demás, el azar por la organización..." (Levi-Strauss, 1988: 68) y, a través 
de ello, actualizar los mecanismos socio-culturales de un sistema de creencias y de valores que para la comunidad es vital; en cuanto a su existencia colectiva.

Contrastar estos aspectos ideológicos y prácticos puestos en juego en torno a una faceta de la muerte en Amaicha del Valle -expresada en la muerte por feminicidio y violación de Doña Esperanza- con los rituales propios de la festividad anual de Ofrenda a la Pachamama, como forma ritualizada, repetitiva, acotada de manera espacial y temporal -que, también, caracterizan a esta comunidad- refuerza las hipótesis planteadas en este artículo; aunque sus continuidades y discontinuidades, no pueden ser expuestos ahora. Lo expuesto hasta aquí; es una línea de investigación de lo relativo a la muerte que ubica en un lugar central a la problemática del género y, como tal, es una primera aproximación a dicha temática en la cual se trabaja sobre la hipótesis de que las significaciones comunitarias acarreadas por la muerte por asesinato de Doña Esperanza Nieva representa el núcleo crítico de un estado actual de la comunidad en el cual se hallan transgredidos gran parte de sus valores tradicionales. Señalar esto no es nada novedoso, aunque indagar en las formas y los mecanismos en que dicha crisis se manifiesta sí lo es.

Frente a esto la movilización que reubicó a las mujeres, transgrediendo a nivel comunitario la centralidad del eje "interno-femenino" hacia otro "externo-masculino" parece hablarnos de un intento colectivo de rectificación ritual de la situación habitual (ya que la muerte acontece siempre ,muchas sin previsión) que fue profundamente interpelada con la muerte de Doña Esperanza Nievasy donde gracias a la movilización de las mujeres, la comunidad amaicheña retuvo por un tiempo de relativa extensión una sensación de crisis de sus creencias y valores que caló hondo. Dicha actualización del sistema tradicional de creencias se habría producido a través del despliegue de un conjunto de aspectos simbólicos e imaginarios, propios de una inversión ritualizada de la "territorialidad simbólica de género", que no se ponen en evidencia con igual fuerza en otros órdenes de la vida comunitaria. Victor Turner (1980), al distinguir el ritual de la ceremonia, le atribuye al primero el carácter de ser transformador, la reubicación territorial de las mujeres de la comunidad indígena de Amaicha debió, si esto es así, haberse transformado; aunque esta es una cuestión que deberá ser abordada mas adelante; en otros tramos de la investigación. 
Marcela López Machado.

Setiembre-Octubre de 2018

Amaicha del Valle. Tucumán.

\section{Bibliografía}

Ardener, Edwin ([1968] 1975) "Belief and the problem of women" "The problema revisited" in Shirley Ardener (edit.) Perceiving women" Malaby Press. África. Reimpreso con autorización de ShirleyArdener en Ellen Levin (edit) (2006) Feminist Antrophology: A reader. Blackwell Publishing. Australia

Chamoux, M. N (1980) Nahuas de Huachinango. México DF. Instituto Nacional Indigenista. Serie de Antropología Social No 73

Chapman, A. (2007) Los Selk'nam. Buenos Aires. Emecé Editores Argentina.

de Marinis, Pablo (2005) "16 comentarios sobre la(s) sociología(s) y la(s) comunidad(es)" en Papeles del CEIC, $\mathrm{N}^{\mathrm{o}}$ 15, CEIC (Centro de Estudios sobre la Identidad Colectiva) Universidad de País Vasco.

(2010) "La comunidad según Max Weber: desde el tipo ideal de Vergemeinschaft hasta la comunidad de los combatientes" en Papeles del CEIC, marzo de 2010 (número monográfico sobre la comunidad en la teoría social clásica y contemporánea). http://www.identidadcolectiva.es/pdf/52.pdf

Durkheim, E (1965) Las Reglas del Método Sociológico. Buenos Aires. La Pléyade.

Eliade, M (1997) Ocultismo, Brujería y Modos Culturales. Barcelona. Paidos.

Ginsburg, C. (1989) "Morelli, Freud y Sherlock Holmes: Indicios y Método Científico" en Eco, U. y Sebeok, T. (eds) El Signo de los Tres. Dupin, Holmes, Peirce. Barcelona. Lumen.

Heritier, F. (1977) "La persona Samo" en Levi-Strauss, Claude (ed.) Seminario La Identidad. Barcelona. Petrel.

(1989) "Simbología del Incesto y de su prohibición" en Izard, M. y Smith, P (Comp.) La Función Simbólica. Barcelona. Jucar.

Hermitte, E. (2004) Poder Sobrenatural y Control Social. Buenos Aires. Editorial Antropofagia. Isla, A (2002) Los Usos Políticos de la Identidad. Indigenismo y Estado. Buenos Aires. Editorial de las Ciencias.

(2003) "Los usos políticos de la memoria y de la Identidad" en Revista Estudios Atacameños $\mathrm{N}^{\circ}$ "\&. Chile. Pp.35-44

(2005) "Estado y Comunidad. Políticas de Identidad" en Revista Nuevo Mundo Nuevos Mundos $\mathrm{N}^{\circ} 5$. http:/nuevomundorevues.org/document33.html

Foster, G. (1974) Tzinzunzan. Los campesinos mexicanos en un mundo de cambio FCE. México.

Levi-Strauss, C. (1968) Antropología Estructural. Buenos Aires. Eudeba.

(1988) Las estructuras elementales del parentesco. Paidós. Barcelona

López Machado, M (1996) Simbolismo y Feminidad. Una revisión del Feminismo. Rosario. Editorial de La Sexta

(2004) "Las mujeres y los salvajes: una reflexión epistemológica" en Revista de la Escuela de Antropología. Vol.IX. Facultad de Humanidades y Artes. UNR. Argentina.

(2010a) "Relaciones entre Género y Compadrazgo en Amaicha del Valle: Una aproximación a su estudio" en Actas de las IV Jornadas de Investigaciones en Diversidad. Centro de Estudios en Diversidad Cultural. Facultad de Humanidades y Artes. UNR. 
(2010b) "Género, Territorio y Comunidad" en VI Jornadas de Investigaciones en Antropología Social. Facultad de Filosofía y Letras. UBA

(2018a) "Un estudio de comunidad en Amaicha del Valle (Valles Calchaquíes. Tucumán): Límites, perspectivas y potencial innovador dentro de los clásicos Estudios.

de Comunidad " en Juan M. Renold (Edit.) Antropología Social. Perspectivas y Problemáticas. Vol. 1. Laborde Editor. Rosario.

(2018b) "COMUNIDAD, GÉNERO Y TERRITORIALIDAD.

Algunas características de las actividades productivas en Amaicha del Valle" en Actas de las $I X$ Jornadas de Investigación en Antropología Social "Santiago Wallace". Sección de Antropología Social del Instituto de Ciencias antropológicas. Facultad de Filosofía y Letras. CABA. Noviembre.

Peirano, M (2002) O Dito e O Feito. Relume Dumará. Río de Janeiro.

Ramos Torres, R. (2010) "La comunidad moral en la obra de Emile Durkheim" en de Marinis, P.; Gatti, D.; Irazuzta, I. (eds) La comunidad como pretexto. En torno al (re)surgimiento de las solidaridades comunitarias. Barcelona, México DF Editorial Anthropos y Universidad Autónoma Metropolitana-Iztapalapa, (383-412)

Redfield, Robert (1941) Yucatán. México. FCE.

(1963) El Mundo Primitivo y sus transformaciones. México DF. FCE.

Rosaldo, Renato (1991) Cultura y Verdad. México. Grijalbo.

Segato Rita (2016) La guerra contra las mujeres. Traficántes de Sueños. Madrid.

Turner, Vïctor (1980) La Selva de los Símbolos. Madrid. Siglo XXI

Siga, Jorge (2010) "Crónica de la muerte de la comunera Esperanza Nieva" en http://ar.globedia.com.

Thomas, Vincent (1991) La muerte, una lectura cultural. Paidos. Barcelona.

Tönnies, Ferdinand. (1947) Comunidad y Sociedad. Buenos Aires. Losada.

Weber, Max ( 1984) Economía y Sociedad. Esbozo de Sociología Comprensiva. México. FCE.

Wolf, Erik (1967) Pueblos y Culturas de Mesoamérica. México Editorial Era. 